School Outcomes among Elementary School-Aged Inuit Children in Inuit Nunangat

\author{
Rubab G. Arim \\ Health Analysis, Statistics Canada \\ Benita Tam \\ Canadian Centre for Climate Modelling and Analysis, Environment Canada \\ Evelyne Bougie \\ Health Analysis, Statistics Canada \\ Dafna E. Kohen \\ Health Analysis, Statistics Canada
}

aboriginal policy studies Vol. 5, no. 2, 2016, pp. 32-59

This article can be found at:

http://ejournals.library.ualberta.ca/index.php/aps/article/view/24702

ISSN: 1923-3299

Article DOI: http://dx.doi.org/10.5663/aps.v5i2.24702

aboriginal policy studies is an online, peer-reviewed and multidisciplinary journal that publishes original, scholarly, and policy-relevant research on issues relevant to Métis, non-status Indians and urban Aboriginal people in Canada. For more information, please contact us at apsjournal@ualberta.ca or visit our website at www.nativestudies.ualberta.ca/research/aboriginal-policy-studies-aps. 


\title{
School Outcomes among Elementary School-Aged Inuit Children in Inuit Nunangat
}

\author{
Rubab G. Arim (1), Benita Tam (2), Evelyne Bougie (3), Dafna E. Kohen (4) ${ }^{1}$
}

\begin{abstract}
The objective of this study was to examine factors associated with school outcomes among elementary school-aged Inuit children in Inuit Nunangat through a socio-ecological framework. The associations among children's school outcomes and various individual, family, and school factors were examined using the 2012 Aboriginal Peoples Survey. Logistic regression analyses suggest that an Inuk child who is healthy and not hungry, whose parents obtained a post-secondary education, who is attending a school with a climate conducive to learning and at which parents are given opportunities to be involved, and who is exposed daily to the Inuit language has better odds of succeeding at school.
\end{abstract}

\section{Introduction}

Education is both a national priority and an important social determinant of health. However, Inuit students in Canada present some of the lowest high school graduation rates (Inuit Tapiriit Kanatami [ITK] 2011). According to the 2011 National Household Survey, approximately half (48 percent) of Inuit aged 25 to 64 do not have a high school diploma, compared to non-Aboriginal (12 percent), Métis (21 percent), and First Nations (33 percent) people of the same age group (Statistics Canada 2011). Rapid social changes over the past decades, poverty and unemployment, geographic isolation, higher suicide rates, and limited language and cultural connections have been cited as barriers to successful schooling for Inuit children (Battiste 2005; Berger 2006). While the need to improve education outcomes among Inuit has long been recognized (ITK 2011), to date, there remains little evidencebased research on factors promoting positive school outcomes among Inuit children.

1 Acknowledgement: The authors would like to thank the anonymous reviewers for their valuable insight and feedback on an earlier version of this article.

Disclaimer: This paper was funded by the Strategic Research Directorate at Indigenous Affairs and Northern Development (AANDC). The views expressed in this document are those of the authors and do not necessarily represent the position of Statistics Canada or AANDC.

Author information: (1) Rubab G. Arim, Health Analysis, Statistics Canada, Rubab.Arim@canada.ca. (2) Benita Tam, Canadian Centre for Climate Modelling and Analysis, Environment Canada, Benita.Tam@ canada.ca. (3) Evelyne Bougie, Health Analysis, Statistics Canada, Evelyne.Bougie@canada.ca. (4) Dafna E. Kohen, Health Analysis, Statistics Canada, Dafna.Kohen@canada.ca.

Corresponding author: Rubab G. Arim, Health Analysis, Statistics Canada, R.H. Coats Building Floor 24 D, 100 Tunney’s Pasture Driveway, Ottawa ON K1A 0T6, Email Rubab.Arim@canada.ca Telephone 613-7975316 Facsimile 613-951-3959.

aboriginal policy studies, vol. 5, no. 2, 2016 
The present study aimed to address this gap by examining some of the factors associated with school outcomes among Inuit children. Using new data from the 2012 Aboriginal Peoples Survey (APS), we sought to explore the following research question: What are the social determinants of Inuit children's success at school? A socio-ecological model of academic achievement (Condly 2006) was selected to investigate this question. This model views school outcomes as being influenced by a wide variety of factors associated with students, their families, and the schools they attend (Rumberger 2011).

There is a call to broaden the definition of how success is measured in Aboriginal learning (Canadian Council on Learning [CCL] 2009), and indeed, Indigenous scholars and communities have been asking for frameworks of pedagogies, assessment, and success that are in line with Indigenous knowledge systems and values (e.g. Battiste 2002; Claypool and Preston 2011; Johnston and Claypool 2010; McGregor 2011; Nunavut Department of Education 2007; Preston et al. 2011). For example, McGregor indicated that Inuit education is most successful when both Inuit culture and Inuit visions for the future are reflected in the education system. In a similar vein, the Nunavut Department of Education (2007) presented an education framework-Inuit Qaujimajatuqangit - that outlines the philosophy of Inuit beliefs that are the basis for curriculum, learning, and teaching in Nunavut schools.

We recognize the crucial importance of Indigenous learning and assessment frameworks in addressing our research question. However, the framework as well as the analytical model used in the present study are restricted to the contents of the 2012 Aboriginal Peoples Survey (APS), and may not correspond fully to the principles of emerging Indigenous-based frameworks. Information from the APS is best viewed as complementing and informingbut not taking the place of-this emerging work.

In the first section of this article, we review the literature pertaining to the socioecological model of school success. In the second part of this article, we use quantitative analytic methods to address our research question, "What are the social determinants of Inuit children's success at school?" Results from our analyses suggest that an Inuk child who is healthy and not hungry, whose parents obtained a post-secondary education, who is attending a school with a climate conducive to learning and at which parents are given opportunities to be involved, and who is exposed daily to the Inuit language has better odds of succeeding at school.

\section{Socio-Ecological Model of School Success}

The economic, health, and social conditions of Inuit are generally more compromised than those of the non-Aboriginal population (Tait 2008). One of the predominant models used to understand school success in a broad context is the socio-ecological model, which considers factors at the individual, family, and community levels (Condly 2006). In this study we also integrate the important dimension of Inuit culture and language to understand the determinants of positive school outcomes among Inuit children. Indeed, studies examining resiliency and success among Aboriginal groups have identified language, culture, and traditional beliefs as influential factors for success (Burack et al. 2007; Fleming and Ledogar 2008). 
In this section, we summarize the literature that contributes to our socio-ecological model of school success. While we draw from the literature pertaining to a wide range of study populations, we recognize that life in Inuit Nunangat-the Inuit homeland in Canada-is very different from life in other parts of Canada for various geographic, social, cultural, and political reasons. Living in the Arctic and sub-Arctic regions of the globe, Inuit are a distinctive Indigenous people with a unique culture and history as well as with a self-government represented by ITK at the national level (Inuit Knowledge Centre 2015). There are no reserves in Inuit Nunangat; Inuit live in municipalities located throughout the four regions of Inuit Nunangat: Nunatsiavut (Labrador); Nunavik (northern Quebec); Nunavut; and the Inuvialuit region (Northwest Territories) (Inuit Knowledge Centre 2015). The primary responsibility for education lies within Inuit governments, a fact that has been accepted as an important element in promoting educational success (Bonesteel and Anderson 2008). Currently, education in Inuit Nunangat is delivered through different public education systems in two territories and two provinces (ITK 2014). Because of the unique context of life in Inuit Nunangat, it should be noted that findings from the literature originating from studies on the general Canadian population and other Indigenous populations may not be applicable to Inuit. We nonetheless include this literature here in an effort to cast a broad net around the issue of academic achievement.

\section{Individual Factors}

Broadly speaking, individual characteristics are important for educational achievement (Hines et al. 2005; Rumberger 2011). Generally, girls tend to do better in school than boys, and younger children tend to do better than older children (Alton-Lee and Praat 2001; Grissom 2004; Mullis et al. 2003); these associations have also been reported for off-reserve First Nations school-aged children (Bougie 2009). Healthy children do better in school compared to children with mental or physical health problems (Jackson and Martin 1998), and having a learning disability has also been associated with lower academic achievement among off-reserve First Nations students (Bougie 2009). Asthma has been particularly associated with less-favourable educational outcomes for children and youth in the general population as well (Kohen 2010).

Although mixed findings exist in the literature (see Guèvremont and Kohen 2012 for a review), the teaching of Indigenous culture and language have been shown to be related to positive school outcomes. Guèvremont and Kohen (2012) found that Inuit children who spoke an Inuit language and learned it in school were more likely to perform well and be motivated to attend school. Similar results have been found for learning an Aboriginal language at home among off-reserve Registered Indian children (Bougie and Sénécal 2010). Culture continuity-in this case, continuity of an Aboriginal languagemay be an influential factor in academic success, as it reinforces personal and cultural identity (Chandler and Lalonde 1998; Hallet et al. 2007; Kirmayer et al. 2011). This is in line with research that suggests that a strong cultural identity is important for the success of Aboriginal students (Battiste 2002; Deyhle and Swisher 1997; Taylor and Wright 2003), and 
that learning, acquiring, and demonstrating fluency in an Aboriginal language contribute to positive self-esteem, which in turn is associated with school achievement (Bougie et al. 2003; Canadian Heritage 2005; Taylor and Wright 2003).

\section{Family Factors}

It is well-documented that family socioeconomic characteristics are associated with educational achievement for children (Rumberger 2011). For instance, food-insecure children are more likely to obtain lower academic scores and to repeat a grade (Alaimo et al. 2004). Among off-reserve Registered Indian children, higher household income and food security, smaller household size, and better housing have all been found to be associated with achievement in school (Bougie and Sénécal 2010). While previous research shows that Inuit live in relatively more disadvantaged social and economic conditions relative to the general Canadian population (Tait 2008), to our knowledge, no studies have examined the associations between family socioeconomic conditions and other family factors and Inuit children's educational outcomes.

Other family characteristics such as family structure, stability, and healthy family relationships have also been shown to be related to school performance (Walker and Shepherd 2008). Generally speaking, family relationships and the family environment cultivate pathways towards school success and resilience (Rutter 1999). Family ties may be particularly important from an Inuit perspective, as a high percentage of Inuit children live in large households (Statistics Canada 2008) with four or more people involved in raising them (Guèvremont 2010). Even at an early age, family involvement has an impact on child learning and development. For example, parental involvement in teaching young children literacy and writing skills was found to be significantly related to early development of literacy skills (Sénéchal and LeFevre 2002). Continuous parental involvement may foster and maintain a positive environment for students as they age. For example, helping with homework was found to be related to successful school performance (Hoover-Dempsey and Sandler 1995). Previous research has suggested that Inuit parents support their children's learning in many ways that are sometimes different from those of middle class Euro-Canadian parents (Berger 2009). For example, Berger notes that Inuit parents would help with homework only if their children asked for help, because student autonomy is valued (2009).

Parental school experiences also have an impact on children's school outcomes. A particular issue for Aboriginal children is the impact of parental experience with residential schooling (Aboriginal Healing Foundation 2002). For instance, First Nations and Registered Indian children living off reserve whose parents did not attend a residential school were found to be more likely to succeed in school than their counterparts with residential-schooled parents (Bougie 2009; Bougie and Sénécal 2010). Parental aspirations for children's education and a child's siblings' school experiences-which may also be associated with parental school experiences-have also been found to play a major role in shaping children's school outcomes. High parental aspirations increase the likelihood of 
school completion and decrease the likelihood of dropping out of school (Alexander et al. 1997; Rumberger 2011). A recent study suggests that Inuit who left school before obtaining their diploma were more likely to have siblings who had also dropped out of school than were Inuit who had graduated (Bougie et al. 2013).

Cognitive stimulation in and outside the home are also a significant attribute of academic success (Gonzales and Padilla 1997). Daily exposure to an Aboriginal language can play an important role in school success, given the relationship between knowledge of an Aboriginal language and positive school outcomes (Guèvremont and Kohen 2012). Access to the Internet at home has been reported to be associated with better academic performance for low-income children (Jackson et al. 2006) -although Internet connections are difficult and costly for many Inuit households (Aboriginal Canada Portal 2005). Reading has also been well-documented as a correlate of academic achievement (Cullinan 2000; Sullivan and Brown 2013). For example, Sénéchal and LeFevre (2002) found exposure to storybooks at a young age to be related to stronger vocabulary and better listening skills. In addition, Bougie (2009) found that reading books every day was associated with doing well in school among young off-reserve First Nations children.

\section{School Factors}

Attending an early childhood development program is often associated with positive cognitive and social outcomes, particularly among children from low-income families (Cleveland and Krashinsky 2003; Palacio-Quintin 2000). High-quality, developmentally appropriate early childhood programs that incorporate cultural aspects and language are particularly beneficial for children and families (Nguyen 2011; Preston et al. 2011). Parental school satisfaction has also been shown to be important for academic outcomes (Charbonneau and Van Ryzin 2012; Rumberger 2011). Previous research has shown that the likelihood of doing well in school was two times higher for off-reserve First Nations children whose parents reported that the school provided information on their children's academic progress, attendance, and behaviour (Bougie 2009).

Characteristics and conditions of schools themselves are also important determinants of students' achievement (Lee and Burkham 2003). In this respect, positive school climate and experiences, including positive support from peers and teachers, have been shown to influence academic achievement (Lee and Smith 1993; Fleming and Ledogar 2008). A recent study has shown that Inuit who had graduated from high school were more likely to report having felt safe and happy at their school than Inuit who left school before obtaining their diploma (Bougie et al. 2013). Further, a study conducted in an elementary school in Alert Bay, British Columbia, Canada, where a majority of the students are Aboriginal, showed that a positive tone and environment decreased the number of situations related to bullying (Bell 2004). Close friendships have also been found to be significantly correlated to educational achievement. Positive friendships may increase the sense of belonging within the school setting, leading to a warmer environment (Baydala et al. 2009). Having friends who have positive school outcomes may set a positive example for individuals. Jackson and 
Martin (1998) argue that a protective factor in school success is at-risk children forging friendships with high achievers. On the other hand, negative peer influences such as bullying can adversely affect academic performance and lead to dropping out of school (Cornell et al. 2013).

Lastly, cultural integration in the school helps cultivate a positive environment. Indeed, the inclusion of culturally meaningful materials in the curriculum, as well as the use of pedagogical approaches that are compatible with traditional Aboriginal learning styles, are regarded as beneficial for Aboriginal students (see Battiste 2002 and Raham 2009 for a review). Schwab (1998) found that the integration of an Aboriginal language into a school curriculum increases community pride, as cultural competence is being maintained within the school system. Similarly, incorporating a cultural framework into education at a secondary school in British Columbia increased overall satisfaction with the school program (Bell 2004). Integrating language and culture in education may help foster a positive environment for children and increase cultural awareness and a sense of self (Baydala et al. 2009; Wright and Taylor 1995).

\section{The Present Study}

Acknowledging a socio-ecological model that views school achievement as being influenced by a wide variety of factors associated with students, their families, and the schools they attend, this study explored the social determinants of positive school outcomes among a nationally representative sample of Inuit children of elementary school age (6 to 13 years old). Using data from the 2012 Aboriginal Peoples Survey (APS), the research question addressed was: What are some of the protective factors that are associated with positive school outcomes among Inuit children? A number of parent-reported school outcomes were available in the 2012 APS, including overall grade average, school attendance, repeating a grade, and receiving or needing tutoring. While these particular indicators do not fully reflect Indigenous learning and assessment frameworks, ${ }^{2}$ these factors have been shown in general population research findings to be linked with school outcomes such as the likelihood of staying in or leaving school (Alexander et al. 1997; Lee and Burkham 2003; Rumberger 2011).

\section{Methods}

\section{Data Source and Sample}

Data were drawn from the 2012 Aboriginal Peoples Survey (APS) - a national survey of First Nations people living off reserve, Métis, and Inuit. The APS was designed to collect information about the social and economic conditions of Aboriginal people in Canada. The 2012 APS represents the fourth cross-sectional cycle of the survey, with a specific focus

2 A more thorough examination of the limitations of these indicators of school success for Inuit children is offered in the Limitations section of this paper. 
on education, employment, and health. The survey was carried out by Statistics Canada, and funded by three federal departments: Aboriginal Affairs and Northern Development Canada, Health Canada, and Employment and Social Development Canada. The target population of the 2012 APS included the self-identified Aboriginal population of Canada living in private dwellings and aged six years and over as of February 1,2012. The data were collected between February 6, 2012 and June 30, 2012. Response to the survey was voluntary. The survey was administered through both Computer Assisted Telephone Interviews and Computer Assisted Personal Interviews. Proxy reporting was used for all children aged 6 to 14 years and for some children aged 15 to 17 years. Respondents were interviewed in the official language of their choice, but for Inuit regions, the questionnaire was translated as a paper copy into Inuktitut (Baffin dialect), and an Inuktitut audio recording of the questionnaire was made to assist interviewers with potential language barriers in the field. The time required to complete the survey varied from person to person, but on average, the survey took about forty minutes to complete. The overall response rate of the 2012 APS was 76 percent. A similar response rate (76 percent) was observed in Inuit Nunangat overall. Response rates for the different regions were as follows: Nunatsiavut, 81 percent; Nunavik, 77 percent; Nunavut, 75 percent; and the Inuvialuit Settlement Region, 71 percent (Cloutier and Langlet 2014).

The sample for the present study includes Inuit children aged 6 to 13 years $(N=699)$ who were attending elementary school (Grades 1-6) and living in one of the four Inuit Nunangat regions (Nunatsiavut [three percent], Nunavik [28 percent], Nunavut [64 percent], and the Inuvialuit Settlement Region [five percent]) at the time of data collection. ${ }^{3}$ For the purpose of the present analyses, these four regions were aggregated, but we should note that the school systems in these four regions, which are provincially and territorially determined, are different. For example, in Nunavik, the Kativik School Board is responsible for the administration and delivery of education. Courses follow the Quebec provincial curriculum, although there are some policy differences. In contrast, in Nunavut, the Nunavut Department of Education is responsible for education throughout the territory (ITK 2007).

\section{Measures}

A number of different items in the 2012 APS pertained to school outcomes. Five parentreported measures included: (1) child's overall grade average on his/her last report card; (2) number of times the child skipped classes and arrived late for school without the parent's permission in the previous two school weeks; (3) whether the child ever repeated a grade; (4) whether the child was receiving or required additional help or tutoring; and (5) number of times the child missed school with the parent's permission in the previous two school weeks. The survey also contained a large number of items about Inuit children's individual, family, and school characteristics. These measures and the five school outcome measures are described in Table 1.

3 More detailed information about the APS is available at http://www.statcan.gc.ca/APS. 


\section{Data Analysis}

Data analysis included three steps. In the first step, descriptive statistics were calculated for all study factors. In the second step, comparison analyses (i.e., chi-square tests) for each of the factors and school outcomes were conducted. Since we originally selected a comprehensive number of factors, the purpose of the comparative analyses was to identify the factors that significantly differentiated between those with positive and negative school outcomes (for example, children who had repeated a grade versus those who had not). Only those factors that had enough sample variance were selected for the comparison analyses. Given our limited sample size and the large number of factors, a decision rule was made that dictated that a factor would be included in the final multivariate analyses only if the results from the comparison analyses were significant for at least two of the five school outcomes. This decision rule also helped avert the possibility of modeling spurious associations between the included factors and the outcomes. In the third step, five logistic regression analyses ${ }^{4}$ (one for each school outcome) were conducted including only those factors that were selected in the second step.

\section{Results}

\section{Descriptive Statistics}

Descriptive statistics for all study factors are presented in Table 2.

\section{Individual Factors}

About 47 percent of children were female and their average age was 8.8 years. The majority of Inuit children ( 80 percent) were in excellent/very good health, and 28 percent were diagnosed with at least one chronic health condition. The four most commonly reported 5 conditions were allergies, asthma, tuberculosis, and speech or language difficulties. Most children's first language learned at home was an Inuit language (79 percent) and about half (53 percent) spoke the Inuit language very well.

\section{Family Factors}

The average household income adjusted for the size of household was $\$ 39,900$. About

4 Logistic regression is a statistical method that allows one to examine associations of a discrete outcome (such as "repeating a grade") with a set of factors. Logistic regression analysis allows one to answer questions such as: Can an outcome (e.g., repeating a grade) be explained by a set of factors? Which specific factors are associated with the outcome? Five models have been developed to illustrate the relationship among each of the five school outcomes and a number of characteristics among Inuit children. The logistic regression computes odds ratios for each characteristic in the model. Odds ratios are used to assess whether children with a specific characteristic (e.g., being in good health) are more or less likely to have repeated a grade than those without the characteristic (the reference group, or those in poor health).

5 Hearing/otitis media difficulties were not assessed in 2012 APS. 
half of Inuit children (49 percent) were reported to have high food security, and similarly, about half (49 percent) were living with two parents. In terms of parental education, 21 percent of Inuit children had mothers/female guardians with post-secondary education (some or completed); a comparable percentage was observed for fathers/male guardians. Approximately 61 percent of Inuit children had grandparents or parents who attended a residential school or a federal industrial school; 24 percent had a sibling who dropped out of school; and 56 percent had parents with hopes that their child would pursue postsecondary education. Nearly 53 percent of children had parents who were involved in four or more school-based activities during the school year, and about 19 percent had a parent or family member who helped with their homework four or more times per week. About 56 percent had access to the internet at home. One in five ( 21 percent) were read to or listened to while attempting to read, and a third (33 percent) read or looked at books outside of school four or more times per week. More than half (56 percent) of Inuit children were reported to have very strong family ties. Regarding language, a majority ( 83 percent) of children had daily exposure to an Inuit language at home, while a similar percentage (85 percent) had daily exposure to an Inuit language outside the home.

\section{School Factors}

Approximately 55 percent of Inuit children had attended an early childhood development or preschool program designed for Aboriginal children. The majority (96 percent) had been taught an Inuit language at school, while nearly half (48 percent) had been taught other subjects in an Inuit language for two or more hours per day at school. About 33 percent had been taught other subjects in an Inuit language for two or more hours per day in kindergarten and Grade 1, suggesting that about a third of Inuit children had an early introduction to Inuit language instruction at school.

A majority of Inuit children had parents who reported that they were receiving information from the school with respect to how their child was doing in school (89 percent), how they could help their child with their homework (79 percent), and why their child was placed in particular groups or classes ( 68 percent). The mean scores for positive and negative school environments (ranging from 1 to 4) were 3.2 and 2.1 respectively, suggesting that Inuit children were attending schools that were rated to be more positive (i.e., students were feeling safe and happy, children were enjoying being at school, and parents were given the opportunity to be involved) than negative (i.e. students perceived racism-, bullying-, alcohol-, drug- and violence-related problems). Most children had parents who reported that their school supported Inuit culture through teaching and/or activities (96 percent).

\section{School Outcomes}

Of the five school outcomes of the study, three of them-namely, high overall grade average (i.e. child received mainly A's), good attendance (i.e. child had not skipped classes or arrived late for school without a parent's permission in the previous two school weeks), 
and the child having missed school with a parent's permission in the previous two school weeks-represented a 50/50 classification. As for the other two outcomes, 11 percent of Inuit children had repeated a grade at some point and 23 percent needed or were receiving additional help or tutoring. "Illness or injury" and "sleeping in or feeling tired" were the two most commonly indicated reasons for missing school with a parent's permission, and "[a need to] enhance [supplement] the school program," "poor academic performance," and "learning difficulty" were the three most commonly reported reasons for needing or receiving tutoring.

\section{Comparison Analyses}

Results from the comparison analyses are presented in Table 3. Two factors (whether the child had ever been taught an Inuit language at school and whether the school supported Inuit culture) were excluded from the comparison analyses because they did not have enough variance - that is, 96 percent of Inuit children had at some point been taught an Inuit language at school and 96 percent were attending schools that supported the Inuit culture. The following factors significantly differed for one of the five school outcomes: the child's gender, chronic conditions, speaking an Inuit language very well, household income, the child's living arrangements, having grandparents or parents who attended a residential school, parental hopes for their child's education, having a parent or family member who helped with the child's homework, strong family ties, daily exposure to an Inuit language in the home, being read to or listened to while attempting to read, and receiving information from the school with respect to how a child was doing in school and how to help with homework.

The factors that differed significantly for at least two of the five school outcomes included the child's age, the child's health status, food security, the father's/male guardian's education, having siblings who never dropped out of school, parental involvement at school, reading books outside of school, daily exposure to an Inuit language outside the home, and positive and negative school environments. All associations were in the expected direction (for example, children who read books outside of school were more likely to have a higher overall grade average). These factors were maintained in the multivariate analyses.

\section{Logistic Regression Analyses}

Five logistic regression analyses (one for each school outcome) were conducted, including only the factors that differed significantly for at least two of the five school outcomes identified in the comparison analyses. The regression analyses examined the relative statistical importance of individual, family, and school factors for school outcomes among Inuit elementary school-aged children (note: while school success in this study was constrained by information reported in the APS, school success also encompasses other important elements not captured in the present study). When considering all included factors simultaneously, analyses revealed that a child's age, general health, food security,

parental education, daily exposure to an Inuit language outside the home, and the school environment were significantly associated with school success (Table 4). 
Specifically, the odds of having had mainly A's on their most recent report cards were nearly two times higher for Inuit children with higher food security and those with a positive school environment than for those without. None of the included factors was significantly associated with school attendance, although most were in the expected direction. The odds of ever repeating a grade were two times lower for Inuit children in excellent/very good health compared to those in good/fair/poor health, and for those with daily exposure to an Inuit language outside the home compared to those with no daily exposure. Children who had daily exposure to an Inuit language outside the home and those who attended a school with a less-negative environment were less likely to need tutoring. Finally, the odds of missing school were almost twice as low for Inuit children whose parents had postsecondary education.

\section{Discussion}

The main objective of this study was to examine some of the factors associated with positive school outcomes among elementary school-aged Inuit children in Inuit Nunangat through a socio-ecological framework. Using a large population-based data source representative of Inuit children, the associations between school outcomes and various parent-reported individual, family, and school factors were examined. Descriptive analyses revealed that a child's age, general health, food security, a father's/male guardian's education, having siblings who never dropped out of high school, parental involvement at school, reading books outside of school, daily exposure to an Inuit language outside the home, and school environment were associated in the expected direction with at least two of the five school outcomes. When looking at these factors simultaneously in the regression analyses, findings revealed that a child's age, general health, food security, parental education, daily exposure to an Inuit language outside the home, and school environment were associated with school outcomes.

Different factors were related to different school outcomes. Younger Inuit children and those with excellent/very good health were less likely to have repeated a grade. Though not statistically significant, the factors of being younger and in excellent/very good health also reflected an association in the expected direction with high overall grade average, better school attendance, and no need for tutoring. These results are consistent with those of other studies that have found an association between younger age and greater school success among off-reserve First Nations and Registered Indian children (Bougie 2009; Bougie and Sénécal 2010). Moreover, though there is an assumption that general health promotes academic success, studies in other populations often focus on the relationship between poor health and school failure (Fowler et al. 1985; Klebanov et al. 1994). In contrast, this study, focusing on positive factors, presents empirical findings on the association between excellent/very good health status and school success among Inuit children.

High food security also emerged as an important factor associated with school outcomes (having mainly A's), supporting past research that has found an association between food security and positive school outcomes in the general population (Alaimo 
et al. 2004) and among off-reserve Registered Indian children (Bougie and Sénécal 2010). Though not statistically significant, high food security also reflected an association in the expected direction with better school attendance and lower absenteeism. Food insecurity along with other factors such as poorer health and poor socio-economic factors may be associated with poor school outcomes by increasing risks to cognitive and psychosocial developmental among children (Alaimo et al. 2004; Fowler et al. 1985). The implications of these results are particularly important because a relatively high proportion of Inuit children experience hunger, especially those who live in Inuit Nunangat (33 percent of children living in Nunavut and in Nunavik, 22 percent in Nunatsiavut, 11 percent in Inuvialuit and three percent outside Inuit Nunangat) (Findlay et al. 2013).

Another family factor that emerged as important was parental education. Having a parent with post-secondary education was significantly associated with lower absenteeism among Inuit children. Though not significant, parental education also reflected an association in the expected direction with the other school outcomes. These findings are in line with other research findings based on non-Indigenous populations that suggest that academic achievement among family members may foster support for school success (Jimerson et al. 1999; Luster and McAdoo 1996). Davis-Kean (2005) argues that parental socioeconomic status is indirectly related to child school success through parent educational hopes and expectations. More specifically, parental support, generally influenced by parents' educational background and experiences, leads to higher school performance among children.

In line with past research suggesting that cultural continuity is an important aspect for academic success (Chandler and Lalonde 1998; Hallet et al. 2007; Kirmayer et al. 2011), our findings show that Inuit children with daily exposure to an Inuit language outside of their home were less likely to have repeated a grade and less likely to have required tutoring. Others have also supported the association between Aboriginal language learning and positive school outcomes (Bougie and Sénécal 2010; Guèvremont and Kohen 2012).

In the presence of individual and family influences, school factors were also found to be associated with school outcomes for Inuit children. Children who attended a school with a positive school environment as defined in the present study were more likely to have a high overall grade average, whereas those who attended a school with a negative school environment were more likely to require tutoring. These findings suggest that while negative school environments - in which bullying, racism, and the presence of alcohol, drugs, and violence are problems-decreased the likelihood of school success, positive school environments-in which children feel safe and happy and where there are opportunities for parental involvement-increased the likelihood of school success. A positive school environment may be critical for school success, as it supports positive student behavior (Finn and Rock 1997; Condly 2006). A positive school environment may be particularly important for those living with parents who have had negative experiences (Dion Stout and Kipling 2003), an association worthy of exploration in future studies. Although family history of residential schooling was examined in the present study, there was only one 
statistically significant association between this factor and the included school outcomes. Future research could examine the processes and perceptions associated with parental residential school attendance as well as its direct and indirect influences on Inuit children's school outcomes.

In summary, using a socio-ecological approach, this study shows that the factors associated with positive school outcomes reported in the APS for young Inuit students in Inuit Nunangat are multifaceted. Indeed, factors promoting positive school outcomes were found at the individual, family, and school levels. Moreover, exposure to the Inuit language outside the home, which represents cultural influences, was also important. These findings, based on a large-scale population survey, are limited in that they do not fully reflect Inuit ways of knowing, learning, and achieving. Nonetheless, this study captures a holistic approach and aligns with the concept of connectedness present in many aspects of Aboriginal cultures (Kenny et al. 2004; Kirmayer et al. 2011), and thus makes a contribution to emerging Indigenous-based education and assessment frameworks.

\section{Limitations}

This study used the 2012 APS as a source of data, and a number of limitations regarding the survey should be acknowledged. First, though this study incorporates factors related to the Inuit language, the limited availability of other factors reflecting cultural influences and emerging Indigenous education and assessment frameworks (e.g. Battiste 2002; Claypool and Preston 2011; Johnston and Claypool 2010; McGregor 2011; Nunavut Department of Education 2007; Preston et al. 2011) is an important limitation of the data and of the present study. Inclusion of more detailed measures of cultural influences and Inuit indicators of school success aligned with Indigenous frameworks would have been of value. For example, measures reflecting the experiential learning of Inuit that occurs outside the classroom-including learning from the land, exposure to Elders, use of traditional skills, and participation in cultural ceremonies (CCL 2009) - would have been of interest.

Another limitation related to the survey includes the use of parent-reported school outcome measures as well as parent-reported individual, family, and school factors. We acknowledge that parents' reporting could have been influenced by many conditions at the time of data collection, such as the language that was used during the survey interview or other potential cultural differences. Moreover, more "objective" school outcomes that may be reported by others (e.g. teachers), such as standardized tests scores, past report card assessments, and administrative records on student attendance over the school year, would circumvent the issue of shared method variance (which can occur when the factors and outcomes are reported by the same individual). Standardized outcome measures developed specifically by and for Inuit are, to our knowledge, limited, and were not available for inclusion in the 2012 APS. Though the school outcomes used in this study have been used as outcome measures in other studies (Bougie 2009; Bougie and Sénécal 2010; Guèvremont and Kohen 2012), self-reported measures may be subjective. It is likely that parents' perceptions are influenced by many factors, including their own experiences 
with schooling and other experiences not captured in the survey. Further research using objective or other measures of school success is required.

As mentioned previously, the validity and cultural relevance of school-related "success" factors for Inuit children also need to be taken into consideration. For example, patterns of school attendance for Inuit children living in Inuit Nunangat may be influenced by the seasonality of certain traditional activities such as hunting. Furthermore, the concept of tutoring could be viewed as reflecting Indigenous values of cooperation, differentiation, and working together for a common cause (Battiste 2002; Nunavut Department of Education 2007), rather than as a measure indicating learning challenges. The content of the APS reflects certain conceptualizations of "school success," but other conceptualizations are also of value. There is a call to redefine how success is measured in Aboriginal learning (CCL 2009), as current conventional measures of school success do not necessarily reflect the specific needs, beliefs, and aspirations of Inuit. In other words, "conventional" measures of school success for Inuit children might not adequately reflect Inuit ways of learning (Berger 2009).

It should also be acknowledged that due to the cross-sectional nature of the APS, our findings do not imply causation. The direction of influence between school outcomes and the included factors is unknown; therefore, findings should be interpreted as associations. Lastly, academic achievement is influenced by experiences over multiple years (Rumberger 2011). Future research examining longitudinal associations between these factors and school success would be an asset to our understanding.

Despite these limitations, this study features several strengths, including the use of a nationally representative sample of Inuit children and the ability to examine various individual, family, and school factors as well as various school outcomes. Our findings highlight the importance of considering multiple factors in promoting school achievement among Inuit children.

\section{Conclusions}

The 2012 APS provided data on children, their family, and their school environments as well as school outcomes that enabled this study to examine a comprehensive set of factors related to school success for Inuit children. This study suggests that an Inuk child who is healthy and not hungry, who has parents who obtained a post-secondary education, who is attending a school with a climate conducive to learning and in which parents are given opportunities to be involved, and who is exposed daily to the Inuit language has better odds of succeeding at school than a child whose life is not characterized by these factors. In addition to contributing to the literature that seeks to understand the factors that promote positive educational outcomes for Indigenous children, our findings provide support for the assertion of the importance of families, schools, and the Inuit language to the educational success of Inuit children. This study has implications for educators, school boards, policy-makers, and researchers interested in promoting positive educational outcomes for Inuit children by highlighting the importance of these associations. Despite the limitations associated with the 2012 APS, future research using the survey as well as other qualitative and quantitative data will undoubtedly continue to make a contribution toward advancing research in this area. 
TABLE 1: Summary of Measures Used in the Study

Factors Description

\section{Individual}

Child demographics

Female

Age

Child health

Parent-rated general health

Diagnosis of at least one chronic health condition

\section{Child language}

First language learned at home in childhood

Skill level for speaking Inuit language

\section{Family}

Socioeconomic status

Household income

Food security

Living arrangements

Mother's or female guardian's highest level of education attained $^{\mathrm{a}}$

Father's or male guardian's highest level of education attained $^{a}$

Family history of and attitudes to education Residential school or federal industrial school attendance

Siblings ever dropped out of school
$\%$ female

In years

Categorized into (0) good/fair/poor (1) excellent/very good health

Presence (yes/no) of asthma or any of the following long-term conditions that have lasted or are expected to last 6 months or more and have been diagnosed by a health professional (i.e., allergies, bronchitis, diabetes, learning disability, attention deficit disorder, emotional difficulties, autism, language difficulties, developmental disability, FASD, or tuberculosis)

First language learned is Inuktitut or Inuinnaqtun or Inuvialuktun (yes/no) Categorized into (1) speaks very well, (2) speaks relatively well, (3) speaks with effort, (4) speaks only a few words, (5) does not speak an Inuit language; and dichotomized categories $2-5$ versus 1

Mean household income adjusted for household size and in $\$ 10,000$ units Categorized into (0) low or very low food security (1) high food security in the household

Categorized into (1) living with two parents, including foster parents or at least one biological or adoptive parent, (2) living with one parent only: mother or father, (3) living with relatives or non-relatives only; dichotomized by combining categories 2-3 versus 1

Categorized into (1) less than high school, (2) High school diploma or equivalent, (3) Some post-secondary education, (4) post-secondary certificate, diploma or degree; dichotomized by combining categories $1-2$ versus 3-4 Categorized into (1) less than high school, (2) High school diploma or equivalent, (3) Some post-secondary education, (4) post-secondary certificate, diploma or degree; dichotomized by combining categories $1-2$ versus 3-4

Grandparents or parents (mother/father) attended a residential school or a federal industrial school (yes/no)

Brothers or sisters ever dropped out of high school (yes/no) 


\section{Factors Description}

Parental hopes for education

Parent/family involvement with school

Parent/family member checks or helps with homework

\section{Social and emotional characteristics}

Family ties

\section{Cognitive stimulation}

Daily exposure to an Inuit language at home Daily exposure to an Inuit language outside the home

Access to the internet at home

Reads aloud to child or listens to child read or attempt to read aloud

Child reads or looks at books, magazines, comics outside of school

\section{School}

Preschool

Attended an early childhood development program or preschool for Aboriginal children

School-language of instruction

Ever been taught an Inuit language in class Ever been taught other subjects in an Inuit language for two or more hours per day Early onset-Ever been taught other subjects in an Inuit language for two or more hours per day in kindergarten and Grade 1
Categorized into (1) no preference or less than high school, (2) high school diploma or equivalent, (3) any level after high school; dichotomized by combining categories 1-2 versus 3

Categorized into (0) not involved or not applicable or involved in 1 activity, (1) involved in 2 activities, (2) involved in 3 activities, (3) involved in 4 or more activities (i.e., speak to teacher, visit class, attend a school event, volunteer in class, help in school, participate in fundraising, participate in other school activities) Categorized into (1) rarely or never, (2) less than once per week, (3) 1-3 times per week, (4) 4 or more times per week; dichotomized by combining categories $1-3$ versus 4

Categorized into (1) no family or very weak ties, (2) moderately strong ties, (3) very strong ties; dichotomized by combining categories $1-2$ versus 3

Yes/no

Yes/no

Yes/no

Categorized into (1) rarely or never, (2) less than once per week, (3) 1-3 times per week, (4) 4 or more times per week; dichotomized by combining categories $1-3$ versus 4 Categorized into (1) rarely or never, (2) less than once per week, (3) 1-3 times per week, (4) 4 or more times per week; dichotomized by combining categories $1-3$ versus 4

Categorized into (1) attended a program designed for Aboriginal children, (2) attended a program not designed for Aboriginal children (or not stated if program designed for Aboriginal children), and (3) has not attended a program; dichotomized by combining categories 2-3 versus 1

Yes/no

Yes/no

Yes/no 


Factors Description

School-provides information

How child is doing in school

How to help with child's homework

Why child is placed in particular groups or classes

Categorized into (1) strongly agree, (2) agree, (3) disagree, (4) strongly disagree; dichotomized by combining categories 1-2 versus 3-4

Categorized into (1) strongly agree, (2) agree, (3) disagree, (4) strongly disagree; dichotomized by combining categories 1-2 versus 3-4

Categorized into (1) strongly agree, (2) agree, (3) disagree, (4) strongly disagree; dichotomized by combining categories $1-2$ versus 3-4

School-environment Positive school environment ${ }^{b}$

Based on 4 items representing positive aspects of school environment such as child feeling safe and happy at school, most children enjoying being at school, and school offering many opportunities for parental involvement; range of scale 1.5-4; Cronbach's alpha $=.78$

Negative school environment ${ }^{b}$

Based on 5 items representing negative aspects of school environment such as presence of racism, bullying, alcohol, drugs, and violence; range of scale 1-4; Cronbach's alpha $=.78$

School supportive of Inuit culture Categorized into (1) strongly agree, (2) agree; (3) disagree, (4) strongly disagree; dichotomized by combining categories $1-2$ versus 3-4

\section{School Outcomes}

High overall grade average [mainly A's]

Overall grade average as a percentage on child's last report card categorized into (1) $80 \%$ or above (mainly As), (2) 70 to $79 \%$ (mainly Bs), (3) 60 to $69 \%$ (mainly Cs), (4) 50 to $59 \%$ (mainly Ds), (5) under $50 \%$ (mainly Es and Fs); (6) no grades given; dichotomized by combining categories 1 versus $2-5 ; 9 \%$ had no grades given and were excluded from analyses.

Attended school

Did not skip classes or arrive late for school in the previous two full school weeks (yes/no) Yes/no

Ever repeated a grade Receives or needs additional help or tutoring

Missed school

Child receives additional help or tutoring or parents or teachers feel additional help or tutoring is required (yes/no)

Missed school once or more with parent's permission in the previous two full school weeks (yes/no)

a These factors were combined in the logistic regression analyses such that the highest education was considered for the mother/father or male/female guardian.

$\mathrm{b}$ These items were subjected to an exploratory factor analysis. The findings indicated that the school environment construct can be described by two factors, namely, positive (four items) and negative (five items) school environments (see Findlay 2013). 
TABLE 2: Descriptive Statistics for all Study Factors (N=699)

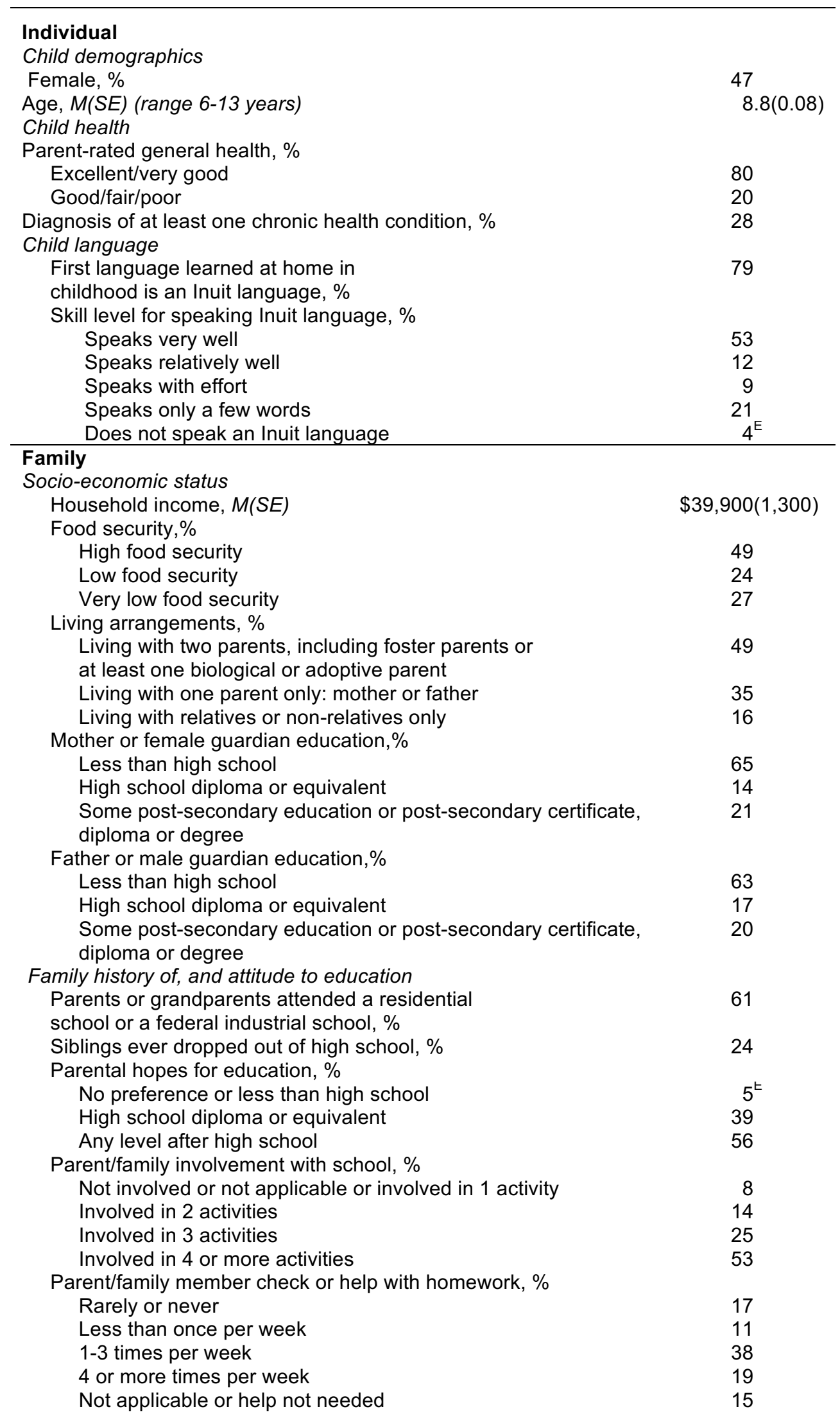


Social and emotional characteristics

Family ties, \%

No family or very weak ties $\quad 23$

Moderately strong ties $\quad 21$

Very strong ties $\quad 56$

Cognitive stimulation

Daily exposure to an Inuit language at home, \% 83

Daily exposure to an Inuit language outside the home, \% 85

Access to the internet at home, \% 56

Reads aloud to child or listens to child read

or attempt to read aloud, \%

Less than 4 times per week $\quad 79$

4 or more times per week $\quad 21$

Childs reads or looks at books, magazines,

comics outside of school, \%

Less than 4 times per week $\quad 67$

4 or more times per week 33

\section{School}

Preschool

Early childhood development program or preschool, \%

Attended a program designed for Aboriginal children 55

Attended a program not designed for Aboriginal children 11

Has not attended 33

School-language of instruction

Ever been taught an Inuit language in class, \% 96

Ever been taught other subjects in $\quad 48$

an Inuit language for two or more

hours per day, \%

Early onset-Ever been taught other

subjects in an Inuit language for two

or more hours per day in kindergarten

and Grade 1, \%

School-provides information

How child is doing in school, \% $\quad 89$

How to help with child's homework, \% $\quad 79$

Why child is placed in particular groups or classes, \% 68

School-environment

Positive school environment, $M(S E)$ (range 1.5 - 4) 3.2(0.02)

Negative school environment, $M(S E)$ (range 1 - 4) 2.1(0.02)

School supportive of Inuit culture, \% 96

\section{School Outcome Factors}

High overall grade average (mainly A's), \% 52

Attended school (did not skip classes or arrive 50

late for school in the previous two full school

weeks), \%

Ever repeated a grade, \% 11

Receives or needs additional help or tutoring, \% 23

Missed school once or more with parent's permission $\quad 49$

in the previous two full school weeks, \%

Note. ${ }^{\mathrm{E}}$ use with caution 


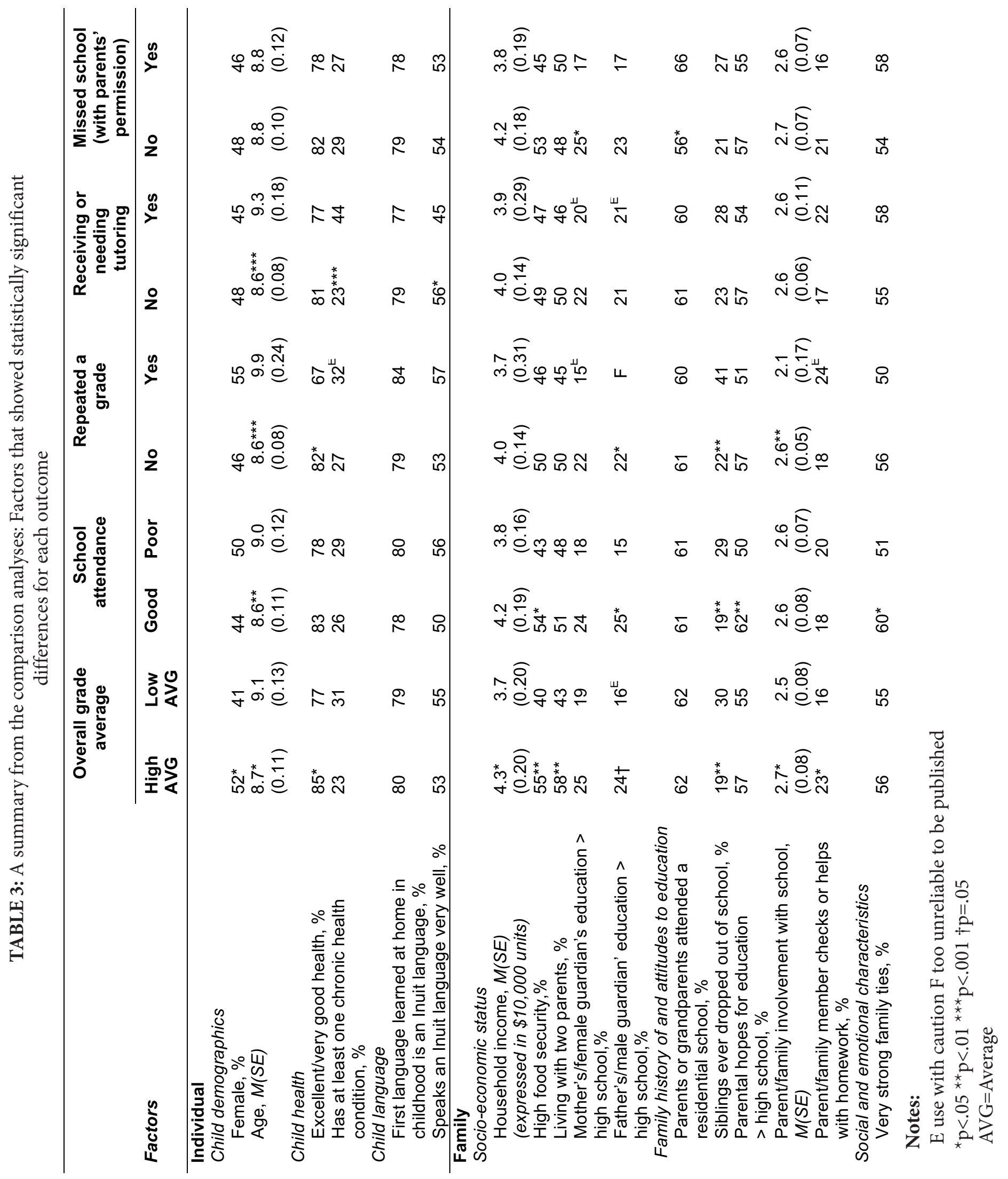




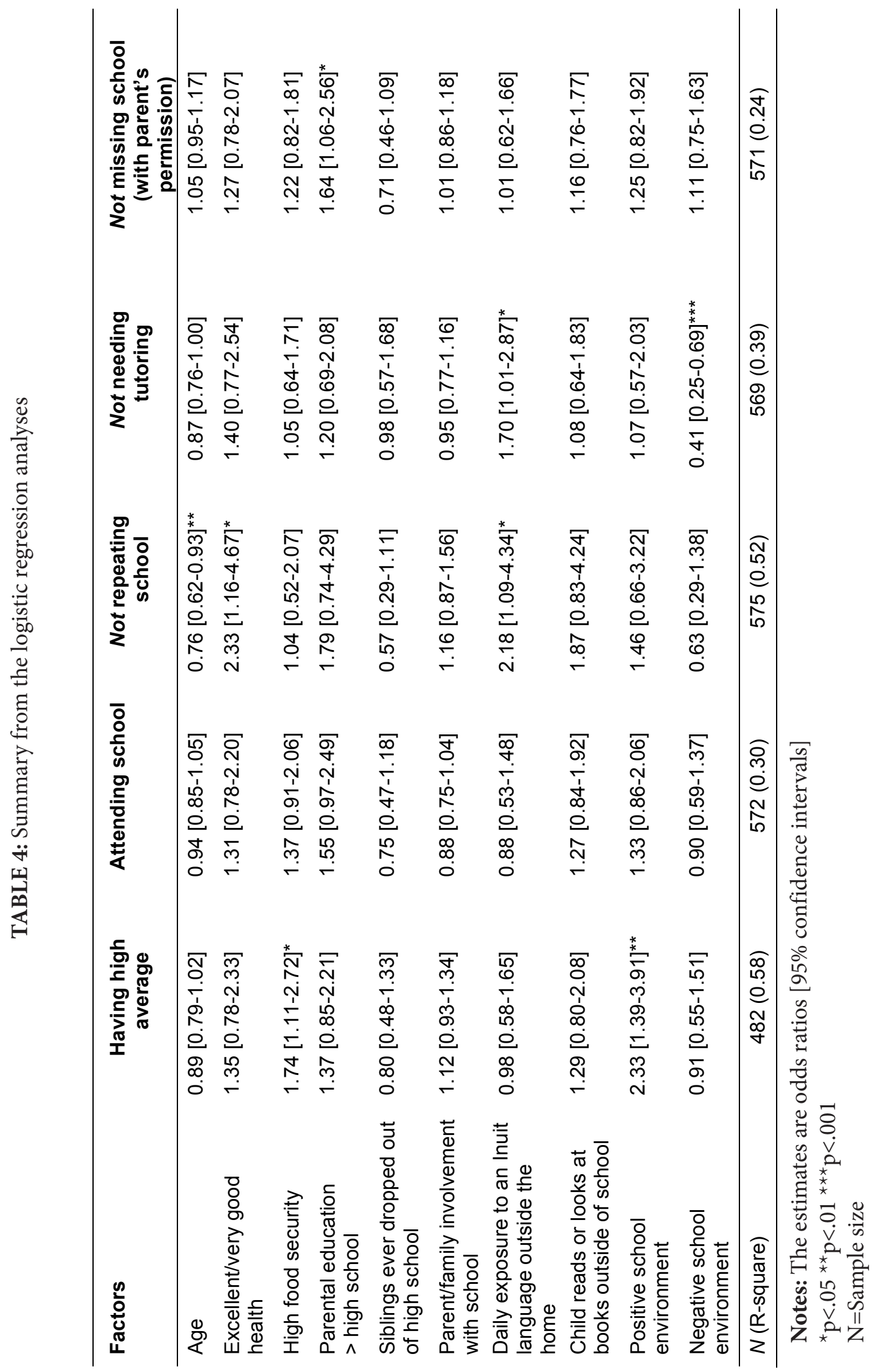




\section{Bibliography}

Aboriginal Canada Portal. 2005. 2004 Report on Aboriginal Community Connectivity Infrastructure. Accessed July 27, 2015. http:/vats.gc.ca/acp/site.nsf/vDownload/ connectivity2004report/\$file/2004ROAC.pdf.

Aboriginal Healing Foundation. 2002. The Healing Has Begun: An Operational Update from the Aboriginal Healing Foundation. Ottawa: Aboriginal Healing Foundation.

Alaimo, K., C.M. Olson, and E.A. Frongillo. 2004. "Food Insufficiency and American School-Aged Children's Cognitive, Academic, and Psychosocial Development." Pediatrics 108(1): 44-53.

Alexander, K.L., D.R. Entwistle, and C.S. Horsey. 1997. "From First Grade Forward: Early Foundations of High School Dropout." Sociology of Education 70: 87-107.

Alton-Lee, A., and A. Praat. 2001. Explaining and Addressing Gender Differences in the New Zealand Compulsory School Sector. A Literature Review. New Zealand Ministry of Education.

Battiste, M. 2002. Indigenous Knowledge and Pedagogy in First Nations Education -A Literature Review with Recommendations. Ottawa: National Working Group on Education and the Minister of Indian Affairs (INAC).

Battiste, M. 2005. State of Aboriginal Learning: Background Paper for the National Dialogue on Aboriginal Learning, Nov. 13-15, 2005. Ottawa: Canadian Council on Learning.

Baydala, L., C. Rasmussen, J. Birch, J. Sherman, E. Wikman, J. Charchun, M. Kennedy, and J. Bisanz. 2009. "Self-Beliefs and Behavioural Development as Related to Academic Achievement in Canadian Aboriginal Children." Canadian Journal of School Psychology 24: 19-33.

Bell, D. 2004. Sharing Our Success: Ten Case Studies in Aboriginal Schooling. Kelowna: Society for the Advancement of Excellence in Education.

Berger, P. 2009. "Inuit Language, Culture, and Parental Engagement in Schooling in One Nunavut Community." Canadian Journal of Native Education 32(1): 73-92.

Berger, T.R. 2006. The Nunavut Project. Nunavut Land Claims Agreement Implementation Contract Negotiations for the Second Planning Period 2003-2013. Vancouver: Conciliator's Final Report. 
Bonesteel, S. and E. Anderson. 2008. Canada's Relationship with Inuit: A History of Policy and Program Development. Ottawa: Indian and Northern Affairs Canada.

Bougie, E. 2009. Aboriginal Peoples Survey, 2006: School Experiences of Off-Reserve First Nations Children Aged 6 to 14. Ottawa: Statistics Canada Catalogue no. 89-637-XNo.001.

Bougie, E., K. Kelly-Scott, and P. Arriagada.2013. The Education and Employment Experiences of First Nations People Living Off Reserve, Inuit, and Métis: Selected Findings from the 2012 Aboriginal Peoples Survey. Ottawa: Statistics Canada Catalogue no. 89-653-X.

Bougie, E., and S. Sénécal. 2010. "Registered Indian Children's School Success and Intergenerational Effects of Residential Schooling in Canada." The International Indigenous Policy Journal 1(1): np.

Bougie, E., S.C. Wright, and D.M. Taylor. 2003. "Early Heritage-language Education and the Abrupt Shift to a Dominant-Language Classroom: Impact on the Personal and Collective Esteem of Inuit Children in Arctic Québec." International Journal of Bilingual Education and Bilingualism 6(5): 349-73.

Burack, J., A. Blidner, J. H. Flores, and T. Fitch. 2007. "Constructions and Deconstructions of Risk, Resilience and Wellbeing: A Model for Understanding the Development of Aboriginal Adolescents." Australasian Psychiatry 15: S18-S23.

Canadian Council on Learning (CCL). 2009. The State of Aboriginal Learning in Canada: A Holistic Approach To Measuring Success. Ottawa: Canadian Council on Learning.

Canadian Heritage. 2005. Towards A New Beginning: A Foundation Report for a Strategy to Revitalize First Nation, Inuit and Métis Languages and Cultures. Ottawa: Report to the Minister of Canadian Heritage by the Task Force on Aboriginal Languages and Cultures. Catalogue no. CH4-96/2005.

Charbonneau, É., and G.G. Van Ryzin. 2012. "Performance Measures and Parental Satisfaction with New York City Schools." American Review of Public Administration 41(1): 54-65.

Chandler, M.J., and C. Lalonde. 1998. "Cultural Continuity as a Hedge against Suicide in Canada’s First Nations.” Transcultural Psychiatry 3(2): 191-219.

Claypool, T.R., and J.P. Preston. 2011. "Redefining Learning and Assessment Practices Impacting Aboriginal Students: Considering Aboriginal Priorities via Aboriginal and Western Worldviews." Indigenous Education in Education: Exploring Our Connective Educational Landscape 17(3): 84-95. 
Cleveland, G., and M. Krashinsky. 2003. Facts and Fantasy: Eight Myths About Early Childhood Education and Care. Toronto: Childcare Resource and Research Unit, University of Toronto.

Cloutier, E., and E. Langlet. 2014. Aboriginal Peoples Survey, 2012: Concepts and Methods Guide. Ottawa: Statistics Canada Catalogue no. 89-653-X- No. 002.

Condly, S.J. 2006. "Resilience in Children: A Review of Literature with Implications for Education." Urban Education 41: 211-36.

Cornell, D., A. Gregory, F. Huang, and X. Fan. 2013. "Perceived Prevalence of Teasing and Bullying Predicts High School Dropout Rates.” Journal of Educational Psychology 105: 138-49.

Cullinan, B.E. 2000. "What Is Independent Reading? Why Is It Important?" Independent Reading and School Achievement 3: 1-25.

Davis-Kean, P.E. 2005. “The Influence of Parent Education and Family Income on Child Achievement: The Indirect Role of Parental Expectations Home Environment." Journal of Family Psychology 19(2): 294-304.

Deyhle, D., and K. Swisher. 1997. "Research in American Indian and Alaska Native Education: From Assimilation to Self-Determination." Review of Research in Education 22: 113-94.

Dion Stout, M., and G. Kipling. 2003. Aboriginal People, Resilience and the Residential School Legacy. Ottawa: Aboriginal Healing Foundation.

Findlay, L.C. 2013. 2012 APS: Analysis of School Climate and Peer Influence Items. Ottawa: Statistics Canada. Unpublished report.

Findlay, L.C., K.A. Langlois, and D.E. Kohen. 2013. "Hunger Among Inuit Children in Canada." International Journal of Circumpolar Health 72: 20324.

Finn, J.D., and D.A. Rock. 1997. "Academic Success among Students at Risk for School Failure." Journal of Applied Psychology 82(2): 221-34.

Fleming, J., and R.J. Ledogar. 2008. "Resilience, an Evolving Concept: A Review of Literature Relevant to Aboriginal Research." Pimatisiwin 6(2): 7-23.

Fowler, M.G., M.P. Johnson, and S.S. Atkinson. 1985. "School Achievement and Absence in Children with Chronic Health Conditions.” The Journal of Pediatrics 106(4): 68387. 
Gonzales, R., and A.M. Padilla. 1997. "The Academic Resilience of Mexican American High School Students." Hispanic Journal of Behavioral Sciences 19: 301-17.

Guèvremont, A. 2010. The Early Learning Experiences of Off-Reserve First Nations Children in Canada. Ottawa: Statistics Canada Catalogue no. 89-644-x.

Guèvremont, A., and D.E. Kohen. 2012. "Knowledge of an Aboriginal Language and School Outcomes for Children and Adults." International Journal of Bilingual Education and Bilingualism 15(1): 1-27.

Grissom, J.B. 2004. “Age and Achievement.” Education Policy Analysis Archives 12(49): 1-42.

Hallett, D., M.J. Chandler, and C.E. Lalonde. 2007. "Aboriginal Language Knowledge and Youth Suicide." Cognitive Development 22: 392-99.

Hines, A.M., P. Wyatt, and J. Merdinger. 2005. "Former Foster Youth Attending College: Resilience and the Transition to Young Adulthood." American Journal of Orthopsychiatry 75(3): 381-94.

Hoover-Dempsey, K.V., and H.M. Sandler. 1995. "Parental Involvement in Children's Education: Why Does It Make a Difference?” Teachers College Record 95: 310-31.

Inuit Knowledge Centre. 2015. Inuit 101. Accessed July 28, 2015. http://www.inuitknowledge.ca/content/inuit-101.

Inuit Tapiriit Kanatami (ITK). 2007 Indigenous Standards in Education: A Discussion Paper for the National Inuit Education Summit. Accessed July 15, 2015. https://www.itk. $\mathrm{ca} /$ publication/itk-education-initiative-education-accord-and-summit-report.

Inuit Tapiriit Kanatami (ITK). 2011. First Canadians, Canadians First. Ottawa: National Committee on Inuit Education. Accessed July 15, 2015. https:/www.itk.ca/ publication/national-strategy-inuit-education.

Inuit Tapiriit Kanatami (ITK). 2014. Milestone Report National Strategy on Inuit Education Interim Report on Milestones 2012-2014. Ottawa: National Committee on Inuit Education. Accessed July 15, 2015. https://www.itk.ca/publication/amaujaqnational-centre-inuit-education-milestone-report.

Jackson, L.A., A. von Eye, F.A. Biocca, G. Barbatsis, Y. Zhao, and H.E. Fitzgerald. 2006. "Does Home Internet Use Influence the Academic Performance of Low-Income Children?” Developmental Psychology 42(3): 429-35.

Jackson, S. and P.Y. Martin. 1998. "Surviving the Care System: Education and Resilience." Journal of Adolescence 21: 569-83. 
Jimerson, S., B. Egeland, and A. Teo. 1999. "A Longitudinal Study of Achievement Trajectories: Factors Associated with Change." Journal of Educational Psychology 91(1): 116-126.

Johnston, A., and T. Claypool. 2010. "Incorporating a Multi-Method Assessment Model in Schools That Serve First Nations, Inuit, and Métis Learners." Native Studies Review 19(2): 121-38.

Kenny, C., E. Faries, J.-A. Fiske, and C. Voyageur. 2004. A Holistic Framework for Aboriginal Policy Research. Ottawa: Status of Women Canada.

Kirmayer, L.J., S. Dandeneau, S. Marshall, M.K. Phillips, and K.J. Williamson. 2011. "Rethinking Resilience from Indigenous Perspectives." The Canadian Journal of Psychiatry 56(2): 84-91.

Klebanov, P.K., J. Brooks-Gunn, and M.C. McCormick. 1994. "School Achievement and Failure in Very Low Birth Weight Children." Journal of Developmental and Behavioral Pediatrics 15(4): 248-56.

Kohen, D.E. 2010. "Impact of Asthma on Children's School Performance." Health Reports 21(4): 1-12.

Lee, V.E., and D.T. Burkham. 2003. "Dropping Out of High School: The Role of School Organization and Structure." American Educational Research Journal 40: 353-93.

Lee, V.E., and J.B. Smith. 1993. "Effects of School Restructuring on the Achievement and Engagement of Middle-Grade Students." Sociology of Education 66(3): 164-87.

Luster, T., and H. McAdoo. 1996. "Family and Child Influences on Educational Attainment: A Secondary Analysis of High/Scope Perry Preschool Data." Developmental Pscyhology 32(1): 26-39.

McGregor, H.E. 2011. Inuit Education and Schools in the Eastern Arctic. Toronto: UBC press. Mullis, I.V.S., M.O. Martin, E.J. Gonzalez, and A.M. Kennedy. 2003. PIRLS 2001 International Report: IEA's Study of Reading Literacy Achievement in Primary Schools. Chestnut Hill, MA: Boston College.

Nguyen, M. 2011. "Closing the Education Gap: A Case for Aboriginal Early Childhood Education in Canada. A Look at the Aboriginal Headstart Program." Canadian Journal of Education 34(3): 229-48. 
Nunavut Department of Education, Curriculum and School Services Division. 2007. Inuit Qaujimajatuqangit Education Framework. Accessed July 15, 2015. http://www.gov. nu.ca/sites/default/files/files/Inuit\%20Qaujimajatuqangit\%20ENG.pdf.

Palacio-Quintin, E. 2000. “Les Services de Garde et le Développement del'Enfant." Canadian Journal of Policy Research / Revue canadienne de recherche sur les politiques 1(2): 25-30.

Preston, J.P., M. Cottrell, T.R. Pelletier, and J.V. Pearce. 2011. "Aboriginal Early Childhood Education in Canada: Issues of Context." Journal of Early Childhood Research 10(1): $3-18$.

Raham, H. 2009. Best Practices in Aboriginal Education: A Review of the Literature and Analysis for Policy Directions. Kelowna: On behalf of the Office of the Federal Interlocutor, Indian and Northern Affairs Canada.

Rumberger, R.W. 2011. Dropping Out: Why Students Drop Out of High School and What Can Be Done About It. Cambridge: Harvard University Press.

Rutter, M. 1999. "Resilience Concepts and Findings: Implications for Family Therapy." Journal of Family Therapy 21: 119-44.

Sénéchal, M., and J.-A. LeFevre. 2002. "Parental Involvement in the Development of Children's Reading Skill: A Five-Year Longitudinal Study." Child Development 73(2): 445-60.

Schwab, R.G. 1998. Educational "Failure" and Educational "Success" in an Aboriginal Community. Canberra: Centre for Aboriginal Economic Policy Research, Australian National University.

Sullivan, A., and M. Brown. 2013. Social Inequalities in Cognitive Scores at Age 16: The Role of Reading. London: Centre for Longitudinal Studies, Institute of Education, University of London.

Statistics Canada. 2008. Aboriginal Peoples in Canada in 2006: Inuit, Métis and First Nations, 2006 Census. Ottawa: Statistics Canada Catalogue no. 97-558-XIE.

Statistics Canada. 2011. 2011 National Household Survey. Ottawa: Statistics Canada Catalogue no. 99-011-X2011037. Data extracted Feb. 14-14.

Tait, H. 2008. Aboriginal Peoples Survey, 2006: Inuit Health and Social Conditions. Ottawa: Statistics Canada Catalogue no. 89-637-No. 001. 
Taylor, D.M., and S.C. Wright. 2003. "Do Aboriginal Students Benefit from Education in their Heritage Language? Results from a Ten-year Program of Research in Nunavik." Canadian Journal of Native Studies 23(1): 1-24.

Walker, R., and C. Shepherd. 2008. "Strengthening Aboriginal Family Functioning: What Works and Why? Australian Family Relationships Clearinghouse." Australian Institute of Family Studies 7: 1-11.

Wright, S.C., and D.M. Taylor. 1995. "Identity and the Language of the Classroom:

Investigating the Impact of Heritage Versus Second Language Instruction on Personal and Collective Self-Esteem." Journal of Educational Psychology 87(2): 241-52. 